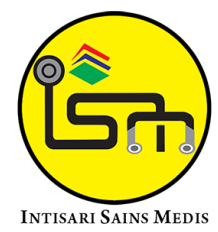

Published by Intisari Sains Medis

\title{
Hemolytic anemia in a 2-years old caused by Glucose 6 Phosphate Dehydrogenase Deficiency (G6PD): a case report
}

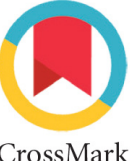

Paulus Arief Budiman*, Ketut Ariawati, Anak Agung Ngurah Ketut Putra Widnyana

Department of Child Health, Faculty of Medicine, Universitas Udayana, Sanglah General Hospital, Bali, Indonesia
*Corresponding to:

Paulus Arief Budiman; Department of Child Health, Faculty of Medicine, Universitas Udayana, Sanglah General Hospital, Bali, Indonesia, paulus.arifbudiman@gmail.com

\section{Received: 2021-08-02}

Accepted: 2021-10-30

Published: 2021-11-04

\section{ABSTRACT}

Background: Glucose-6-Phosphate-Dehydrogenase (G6PD) deficiency is an enzyme abnormality related to sex chromosomes (x-linked), which is inherited. The activity or stability of the G6PD enzyme decreases, thus causing the breakdown of red blood cells when an individual is exposed to exogenous substances that can cause oxidative damage. This case study aims to describe a rare case of hemolytic anemia caused by glucose 6 phosphate dehydrogenase deficiency in a two-year-old boy.

Case Presentation: A two-year-old boy presented with agitated, pale, yellowish eyes and body and projectile vomiting after consuming fava beans. He had a prior history of packed red cell transfusion. Physical examination found the conjunctivae were pale with the icteric sclera. Laboratory examination revealed leukocytosis, moderate normochromic normocytic anemia, increased reticulocytes count, and elevated total and unconjugated bilirubin. Peripheral blood smear examination found microcytes, spherocytes, fragmentocytes, and burr cells. Coomb test was negative with decreased G6PD result.

Conclusion: G6PD deficient patients have no symptoms until exposed to oxidizing drugs, infections or after fava beans ingestion which may cause hemolytic anemia and jaundice. Several methods of screening and diagnosis of G6PD can be performed to avoid morbidity and mortality.
Keywords: Glucose-6-Phosphate Dehydrogenase, Hemolytic Anemia, Fava Bean

Cite This Article: Budiman, P.A., Ariawati, K., Widnyana, A.A.N.K.P. 2021.Hemolytic anemia in a 2-years old caused by Glucose 6 Phosphate Dehydrogenase Deficiency (G6PD): a case report. Intisari Sains Medis 12(3): 817-821. D0I: 10.15562/ ism.v12i3.1159

\section{INTRODUCTION}

Glucose-6-Phosphate Dehydrogenase (G6PD) is an enzyme that catalyzes reactions to the pentose phosphate pathway and provides a reducing effect on all cells in the form of NADPH (the reduced form of nicotinamide adenine dinucleotide phosphate). ${ }^{1}$ Nicotinamide Adenine Dinucleotide Phosphate (NADPH) compounds enable cells to survive oxidative stress, which can be triggered by several oxidant substances and provide glutathione in a reduced form. Erythrocytes do not have mitochondria, so the pentose phosphate pathway is the only source of NADPH, so it depends on G6PD as the main power supply. ${ }^{1}$

The role of the G6PD enzyme in maintaining the integrity of red blood cells and avoiding hemolytic events lies in their function in the pentose phosphate pathway. ${ }^{2}$ In the red blood cell, there is a reduced Glutathione Sulfhydryl (GSH) compound that is able to maintain the integrity of the sulfhydryl (SH) group in hemoglobin and red blood cells. The function of GSH is to maintain cysteine residues in hemoglobin and other proteins in the erythrocyte membrane to remain in the reduced and active form, maintain hemoglobin in ferrous condition, maintain the normal structure of red blood cells, and play a role in the detoxification process. ${ }^{2}$ GSH is the second substrate for the enzyme glutathione peroxidase, where it neutralizes hydrogen peroxide, an oxidant that can cause oxidative damage to red blood cells. ${ }^{2}$

G6PD deficiency is an X-linked, hereditary genetic defect caused by mutations in the G6PD gene, resulting in protein variants with different levels of enzyme activity levels associated with a wide range of biochemical and clinical factors phenotypes. The gene encoding G6PD is found on the long arm of the X chromosome (xq28) and consists of 13 axons with a length of $18 \mathrm{~kb}{ }^{3}$

High prevalence is found in Africa, the Mediterranean, Southeast Asia and Latin America. In the United States, black males are most commonly affected, with a prevalence of approximately 10 percent. ${ }^{4}$ A higher incidence is found in males than females. In Greece, where this disease is endemic, an estimated 225.000 males and 92.000 females are affected. ${ }^{5}$ In Indonesia, the prevalence of G6PD deficiency reaches $2.7 \%$ to $14.2 \%{ }^{4}$ Soemantri AG et al., testing 169 Javanese males in Central Java, documented a G6PD deficiency was $14 \%{ }^{6}$ A previous study from Jalloh A et al., is consistent with this trend, with the 
Javanese registering the highest values. ${ }^{7}$

Most people with G6PD defects are asymptomatic and do not know their condition. This disease arises when erythrocytes experience oxidative stress triggered by drugs, infections, or the consumption of fava beans. G6PD deficiency usually manifests as acute hemolytic anemia induced by drugs or infections, favism, neonatal jaundice and chronic non-spherical hemolytic anemia. ${ }^{1,8}$ Acute hemolysis in patients with G6PD deficiency is usually characterized by weakness, back pain, anemia and jaundice. An increase in unconjugated bilirubin levels, lactate dehydrogenase and reticulocytosis are markers of the disorder. ${ }^{1,8,9}$

The gold standard for diagnosis of G6PD deficiency can be categorized as either genotyping assays, which determine at the DNA level whether someone is G6PD deficient, or phenotyping assays, which measure the G6PD activity in the individual's blood. ${ }^{4}$ Phenotypic assays can be quantitative (providing a precise measure of G6PD activity) is based on enzymatic activity with quantitative analysis of NADPH production level spectrophotometry from NADP or qualitative (indicating normal or abnormal activity). ${ }^{4} \quad$ Several semi-quantitative methods have been developed for rapid screening, such as the fluorescent spot tests (FST) that indicate G6PD deficiency if blood spots do not fluoresce under ultraviolet light. ${ }^{10}$ The quantitative method is available in Indonesia.

The most effective management strategy for G6PD deficiency to prevent hemolytic is to avoid oxidative stress (for example, drugs and fava beans). Acute hemolytic due to G6PD is usually short and no specific treatment is needed. In rare cases (usually children), severe anemia may occur and requires a blood transfusion. ${ }^{1,8}$ Based on those mentioned above, this case study aims to describe the clinical presentation, diagnosis and management of hemolytic anemia caused by G6PD deficiency.

\section{CASE REPORT}

A two-year-old boy was brought to the pediatric Emergency Department (ED) Sanglah Hospital by his parents with a chief complaint of yellowish skin, generalized weakness and pale since the night before. The patient also complained of vomiting since the night before, with a total frequency of 4 times. The volume of each vomit was $1 / 4$ glass of mineral water containing the food consumed before; no blood was found. Two days before hospitalization, he consumed two small sacks of fava beans. He took fava beans for the first time.

The patient presented with pale since two days before admission and getting worst since yesterday. The yellowish skin appeared one day before being admitted to Sanglah Hospital. It initiated slightly, then spread all over his body. No complaint of fever, shortness of breath or cough was found. The patient denied chills, rigors, dyspnea, weight loss, and lymphadenopathy. There was no history of nosebleeds, bleeding gums, black stool. The color of the stool was yellow, without blood, no mucous and no fat. The delivery history showed that he was born spontaneously at Sanglah Hospital, cried spontaneously, and had a birth weight of 3200 grams and gestational age of 9 months. No history of jaundice since the born and maternal history of consuming oxidative agents was denied. The immunization status was completely related by age. The growth chart of the patient showed normal growth with no developmental disorders. The urine's color was like tea.

\section{Table 1. The initial laboratory findings of a patient with a history of PRC and ursodeoxycholic acid administration}

\begin{tabular}{lcc}
\hline \multicolumn{1}{c}{ Variable } & Values & Unit \\
\hline Leucocyte & 1.84 & $10^{3} / \mu \mathrm{L}$ \\
Hemoglobin & 3.60 & $\mathrm{~g} / \mathrm{dL}$ \\
MCH & 34.40 & $\mathrm{pg}$ \\
MCV & 91.30 & $\mathrm{fL}$ \\
MCHC & 37.70 & $\mathrm{fL}$ \\
PLT & 367 & $10^{3} / \mu \mathrm{L}$ \\
SGOT & 46.00 & $\mathrm{U} / \mathrm{L}$ \\
SGPT & 18.00 & $\mathrm{U} / \mathrm{L}$ \\
Total Bilirubin & 14.02 & $\mathrm{mg} / \mathrm{dL}$ \\
Direct Bilirubin & 2.44 & $\mathrm{mg} / \mathrm{dL}$ \\
\hline
\end{tabular}

MCH: Mean Corpuscular Hemoglobin; MCV: Mean Corpuscular Volume; MCHC: Mean Corpuscular Hemoglobin Concentration; PLT: Platelet; SGOT: Serum Glutamic Oxaloacetic Transaminase; SGPT: Serum Glutamic Pyruvic Transaminase 
hemoglobin level (6.37 g/dL), MCV (84.24 fL), MCH (29.39 pg), MCHC (34.89 g/ $\mathrm{dL}), \mathrm{RDW}(13.20 \%)$, and platelet counts $\left(244 \times 10^{3} / \mu \mathrm{L}\right)$, reticulocyte count $(5.6 \%)$, Corrected Reticulocyte Count (CRC) $(2.37 \%)$, and blood smear indicated normochromic normositer in erythrocyte as well as leucocyte negative young cell. Results of his Liver Function Test (LFT) showed SGOT was at $58.4 \mathrm{U} / \mathrm{L}$, followed by SGPT $(17.00 \mathrm{U} / \mathrm{L})$, total bilirubin (10.87 mg/dL), direct bilirubin $(1.29 \mathrm{mg} /$ $\mathrm{dL})$, indirect bilirubin $(9.58 \mathrm{mg} / \mathrm{dL})$, and the result of electrolyte was normal (Table 2). Based on the laboratory finding, which hemoglobin was low, MCV and MCHC were normal, and bilirubin total and bilirubin direct were high. Those indicated anemia normochromic normositer caused by hemolytic anemia. In this case, blood smear examination could not be applicated, because the result could be affected by donor blood.

The patient was diagnosed with moderate normochromic normocyte anemia caused by G6PD deficiency with a well-nourished differential diagnosis of autoimmune disease. Planning diagnosis for this patient was evaluation blood smear, reticulocyte, and coomb test. Planning treatment for this patient was ursodeoxycholic acid $10 \mathrm{mg} / \mathrm{kg} /$ times $100 \mathrm{mg} 3$ times per day.

Three days after being admitted, the condition improved; no fever, jaundice disappeared. The patient underwent several laboratory evaluations. His results showed that hemoglobin level increased at $8.42 \mathrm{~g} / \mathrm{dL}$, reticulocyte level $8.7 \%$ and corrected retic was elevated at 4.2. Blood smear found normochromic normocytic, anisopoikilocytosis (microcyte $(+)$, spherocytes $(+)$, fragmentocyte $(+)$, burr cells $(+))$, normoblast, lymphoblast cell was not found, platelet was normal. The impression of blood smear was normochromic normocytic anemia, and Coomb test examination was negative.

Nine days after being admitted, the condition was better. The patient underwent laboratory evaluation. His complete blood counts were as follows: hemoglobin level increased at $9.25 \mathrm{~g} / \mathrm{dL}$, hematocrit was normal at $27.67 \%$ and thrombocyte level was normal at 314000 $10^{3} / \mu \mathrm{L}$. The differential count showed $40,23 \%$ lymphocytes, $46,08 \%$ neutrophil. The result of glucose 6 phosphate

Table 2. The laboratory findings during admission

\begin{tabular}{lcc}
\hline \multicolumn{1}{c}{ Variable } & Values & Unit \\
\hline Leucocyte & 19.93 & $10^{3} / \mu \mathrm{L}$ \\
Lymphocyte & 19.98 & $\%$ \\
Neutrophil & 72.11 & $\%$ \\
Monocytes & 6.38 & $\%$ \\
Hemoglobin & 6.37 & $\mathrm{~g} / \mathrm{dL}$ \\
MCH & 29.39 & $\mathrm{pg}$ \\
MCV & 84.24 & $\mathrm{fL}$ \\
MCHC & 34.89 & $\mathrm{fL}$ \\
PLT & 244 & $10^{3} / \mu \mathrm{L}$ \\
SGOT & 58.4 & $\mathrm{U} / \mathrm{L}$ \\
SGPT & 17.00 & $\mathrm{U} / \mathrm{L}$ \\
Total Bilirubin & 10.87 & $\mathrm{mg} / \mathrm{dL}$ \\
Direct Bilirubin & 1.29 & $\mathrm{mg} / \mathrm{dL}$ \\
Indirect Bilirubin & 9.58 & $\mathrm{mg} / \mathrm{dL}$ \\
RDW & 13.20 & $\%$ \\
Reticulocyte & 5.6 & $\%$ \\
\hline
\end{tabular}

MCH: Mean Corpuscular Hemoglobin; MCV: Mean Corpuscular Volume; MCHC: Mean Corpuscular Hemoglobin Concentration; PLT: Platelet; SGOT: Serum Glutamic Oxaloacetic Transaminase; SGPT: Serum Glutamic Pyruvic Transaminase; RDW: Red Cell-Distribution Width dehydrogenase decreased to 5,8. The patient was discharged.

\section{DISCUSSION}

Glucose-6-phosphate dehydrogenase (G6PD) is an enzyme that catalyzes the first reaction of pentose shunt catalyzes the oxidation of glucose 6 phosphate to 6 phospho-gluconolactone, which reduces Nicotinamide Adenosine dinucleotide (NADP+) to Nicotinamide Adenosine Dinucleotide Phosphate (NADPH). This enzyme is present in the cytoplasm, spread throughout cells of varying degrees. ${ }^{1}$ In Red Blood Cells, the pentose shunt is the only source of NADPH, which is crucial in maintaining high cellular levels of glutathione to protect the cell from oxidative stress-induced damage. Nicotinamide adenosine dinucleotide phosphate levels are maintained by G6PD; thus, in G6PD deficient RBC, glutathione is not restored to adequate levels under oxidative stress, leading to a buildup of free radicals and insoluble hemoglobin within the cell. ${ }^{1-3}$ Glucose-6-phosphate dehydrogenase activity decreases significantly as erythrocytes age, with a half-life of about 60 days. ${ }^{11}$

The inheritance of G6PD deficiency shows a typical X-linked pattern. Males are homozygous for the G6PD gene and can have normal gene expression or be G6PD deficient. ${ }^{1}$ Female who has two copies of the G6PD gene on each $\mathrm{X}$ chromosome may be homozygote or heterozygote, it can have normal gene expression or be heterozygous. ${ }^{3}$ Heterozygous females are genetic mosaics due to $\mathrm{X}$ chromosome inactivation (in any cell, one $\mathrm{X}$ chromosome is inactive, but different cells randomly inactivate one chromosome or the other). ${ }^{3}$ The abnormal cells of a heterozygous female can be as deficient for G6PD as those of a G6PD deficient male: therefore, such females can be susceptible to the same pathophysiological phenotype. ${ }^{8}$ In this case, the patient was a male with a G6PD level lower than normal. So, the genotype should be G6PD deficiency hemizygote.

The acute and severe hemolytic syndrome due to fava beans is called Favism. Favism is similar to drug-induced hemolysis. The case of hemolytic crisis due to fava beans in children with G6PD 
deficiency was rare and a similar case was also reported in Nepal. ${ }^{12}$ In Indonesia, the incidence of fava bean-induced hemolytic crisis was not known.

Meloni $\mathrm{T}$ et al., have found that the highest incidence of favism or druginduced hemolytic anemia occurred in children aged 2-6 years. ${ }^{12}$ In comparison, children below two years of age made up only $4.5 \%$. In contrast, those over six years of age constituted $22.3 \% .{ }^{12}$ Favism presents as acute hemolytic anemia, usually around 24 hours after the beans are eaten. ${ }^{12}$ Typically, a hemolytic attack initiates with malaise, weakness, and abdominal pain. Patients' chief complaints can be described as a triad of urine discoloration, jaundice, and vomiting (59\%), which can be considered the triangle of classic favismtriggered hemolysis. ${ }^{13}$ The presentation of this disease depends mainly on the degree of deficiency and the severity of hemolytic attacks. A previous study showed that younger patients tend to present with a significant severe form of hemolysis, more prolonged exposure, and the rural areas tend to present with more severe episodes of hemolysis. ${ }^{14}$ In this case, the patient was two years old, lived from the rural regions of Bangli and the duration of hemolysis after the exposure of fava bean was one day before the symptom.

Fortunately, most G6PD deficient individuals are asymptomatic throughout their life and unaware of their status. The illness generally manifests as acute hemolysis, which usually arises when red blood cells undergo oxidative stress triggered by agents such as the ingestion of fava beans, infection, or drugs. Fava bean ingestion is the most common precipitating factor for hemolysis in G6PD deficient populations. ${ }^{12,14}$ Infections such as hand-foot-mouth disease, enteroviruses, hepatitis A, typhoid fever, and pneumonia trigger hemolysis in G6PD deficient persons. Consumption of some antibiotics, antimalarial agents, aspirin, and sulfonamides, also induces hemolysis in these patients..$^{15} \mathrm{~A}$ previous study showed that hemolytic crises were significantly more common in spring, the peak time for fava bean consumption, and occurred more frequently in those with a family history of G6PD deficiency, especially in females. ${ }^{15}$ Fava bean intake (93\%) was the first etiological agent triggering hemolysis, followed by infectious agents and drug consumption. ${ }^{15}$ The high prevalence of G6PD deficiency in Iran, we should emphasize the education of parents and physicians about the disease and prevention of fava bean ingestion in people with G6PD deficiency. In this case, G6PD deficiency is caused by the consumption of fava bean one day before hospitalization.

The definitive diagnosis of G6PD deficiency is based on the estimation of enzyme activity by quantitative spectrophotometric analysis of the rate of NADPH production from NADP. ${ }^{4,5}$ For rapid population screening, several semi quantitative methods have been applied, such as the dye-decoloration test and fluorescent spot tests, which indicate G6PD deficiency when the blood spot fails to fluoresce under ultraviolet light. ${ }^{16}$ Another semi quantitative tests have been used but require definitive testing to confirm an abnormal result. ${ }^{17}$ In this case, the patient had titer G6PD of $5.8 \mathrm{U} / \mathrm{gr} \mathrm{Hb}$ (less than $10 \%$ of normal) with no chronic hemolytic anemia; therefore, based on the enzyme activity, the patient was classified as having type II.

Reticulocytes are immature nonnucleated erythrocytes that are released from the bone marrow following enucleation of the normoblast. ${ }^{18}$ Because the reticulocyte stage of erythroid differentiation only lasts a few days, the number of reticulocytes in the blood is a useful clinical indicator of the rate of erythropoiesis. ${ }^{18}$ Since reticulocyte enumeration provides information about the bone marrow activity and the effectiveness of red blood cell production, it is crucial in the clinical application of reticulocytes parameters to aid the diagnosis of anemic patients, and for monitoring bone marrow transplantation patients, patients undergoing therapy with marrow toxic drugs, and patients being treated for anemia. ${ }^{19}$ In the condition of massive hemolysis, an elevated reticulocyte count would be expected in a normally functioning bone marrow. The RBC membrane's compromised integrity results in intravascular hemolysis and rapid removal of these cells within the splenic pulp. ${ }^{9}$ In this case, the reticulocyte was elevated $8.2 \%$, which the normal value of reticulocytes is $1-2 \%$.
A blood smear is particularly important in the diagnosis of acute hemolysis induced by oxidant damage. ${ }^{20}$ Oxidant-induced hemolysis is most often seen in glucose 6 phosphate dehydrogenase (G6PD) deficiency. Precipitated hemoglobin is disruptive to the structure and function of the RBC membrane and leads to increased membrane permeability, osmotic fragility, and cell rigidity. ${ }^{21}$ Direct examination of blood under a microscope in a peripheral blood smear may demonstrate red blood cell fragments called schistocytes, red blood cells that look like spheres (spherocytes), and/or red blood cells missing small pieces (bite cells). ${ }^{20,21}$ Many hemolytic anemias show multiple poikilocytes: G6PD deficiency, for example, often leads to a bite and blister cells and schistocytes and spherocytes. The RBC morphology may not suggest a single diagnosis as several relevant avenues for clinical and laboratory follow-up. A patient with bite cells and spherocytes may benefit from G6PD screening. ${ }^{22}$ Bite and blister cells and irregularly contracted cells are the classic findings in oxidative hemolysis: for example, because of G6PD deficiency. Oxidative hemolysis may also lead to (less prominent) schistocytosis and spherocytosis. ${ }^{20}$ In this case, the blood smear was normochromic normocytic erythrocyte, anisocytosis and poikilocytosis (microcyte $(+)$, spherocytes $(+)$, fragmentocyte $(+)$, burr cells $(+))$, normoblast.

The most effective management strategy for G6PD deficiency is to prevent hemolysis by avoiding oxidative stressors. ${ }^{1}$ Infection can cause hemolysis as well and should be treated appropriately. The general principle of care, including exchange transfusion for neonatal hyperbilirubinemia and RBC transfusion for the hemolytic crisis. ${ }^{23}$ This approach requires the patient to be aware of their deficiency as a result of a previous hemolytic episode or a screening program. Fortunately, acute hemolysis in G6PD deficient individuals usually happens shortly and does not need specific treatment. In rare cases (usually children), acute hemolysis leading to severe anemia may require transfusions of red blood cells. ${ }^{2}$ Splenectomy generally is not recommended. Folic acid and iron potentiallyareusefulinhemolysis, although 
G6PD deficiency usually is asymptomatic, and the associated hemolysis usually is short-lived. Antioxidants such as vitamin $\mathrm{E}$ and selenium have no proven benefit for the treatment of G6PD deficiency. ${ }^{4}$ In this case, He had a good clinical condition after he had got RBC transfusions and avoided consuming fava bean.

G6PD deficiency could inhibit 3-hydroxy-3-methyl glutaryl coenzyme A (HMG-CoA) reductase used for cholesterol synthesis or cytochrome P 450 enzymes used for steroid metabolism. ${ }^{24,25}$ It can affect decreased production of androgen. No studies have systematically assessed how G6PD deficiency affects health across the life course, especially from an evolutionary biology perspective that early life survival might trade-off against reproduction and/or growth and development. ${ }^{1}$ To examine the association of G6PD) deficiency with adolescent physical and mental health, a previous study showed that G6PD deficient adolescents had broadly similar physical and mental health indicators but transiently lower BMI gain and later pubic hair development, whose long-term implications warrant investigation. ${ }^{26}$ In this case, the current sufferer is 2 years old. Parents should be given education on the importance of monitoring the growth and development of the child into adulthood.

\section{CONCLUSION}

A two-year-old boy presented anxiety, vomiting 4 times without nausea, and headaches since the night before. It happened after consuming fava beans. The diagnosis of G6PD deficiency was established based on clinical features and laboratory investigation. The patient is in good clinical condition after he had got RBC transfusions. The patient prognosis was good, and no complications were found as well as the hemolysis was immediately resolved.

\section{CONFLICT OF INTEREST}

There is no competing interest regarding the manuscript.

\section{ETHICS CONSIDERATION}

This case study has obtained informed consent from the patient and followed publication ethics protocol based on COPE and ICMJE guidelines.

\section{FUNDING}

None.

\section{AUTHOR CONTRIBUTIONS}

All authors equally contribute to the study from the conceptual framework, data acquisition, data analysis until reporting the case study results through publication.

\section{REFERENCES}

1. Cappellini MD, Fiorelli G. Glucose-6phosphate dehydrogenase deficiency. Lancet. 2008;371(9606):64-74.

2. Mehta A, Mason PJ, Vulliamy TJ. Glucose-6phosphate dehydrogenase deficiency. Baillieres Best Pract Res Clin Haematol. 2000;13(1):2138.

3. Luzzatto L. Glucose 6-phosphate dehydrogenase deficiency: from genotype to phenotype. Haematologica. 2006;91(10):13031306.

4. Frank JE. Diagnosis and management of G6PD deficiency. Am Fam Physician. 2005;72(7):1277-1282.

5. Reclos GJ, Hatzidakis CJ, Schulpis KH. Glucose6-phosphate dehydrogenase deficiency neonatal screening: preliminary evidence that a high percentage of partially deficient female neonates are missed during routine screening. J Med Screen. 2000;7(1):46-51.

6. Soemantri AG, Saha S, Saha N, Tay JS. Molecular variants of red cell glucose-6phosphate dehydrogenase deficiency in Central Java, Indonesia. Hum Hered. 1995;45(6):346350. doi:10.1159/000154303

7. Jalloh A, Tantular IS, Pusarawati S, Kawilarang AP, Kerong H, Lin K, et al. Rapid epidemiologic assessment of glucose-6-phosphate dehydrogenase deficiency in malaria-endemic areas in Southeast Asia using a novel diagnostic kit. Trop Med Int Health. 2004;9(5):615-23.

8. Ronquist G, Theodorsson E. Inherited, nonspherocytic haemolysis due to deficiency of glucose-6-phosphate dehydrogenase. Scand J Clin Lab Invest. 2007;67(1):105-111.

9. Minucci A, Giardina B, Zuppi C, Capoluongo E. Glucose-6-phosphate dehydrogenase laboratory assay: How, when, and why? IUBMB Life. 2009;61(1):27-34.

10. Thielemans L, Gornsawun G, Hanboonkunupakarn B, Paw MK, Porn P, Moo PK, et al. Diagnostic performances of the fluorescent spot test for G6PD deficiency in newborns along the Thailand-Myanmar border: A cohort study. Wellcome Open Res. 2018;3(1):1-12.

11. Luzzatto L, Nannelli C, Notaro R. Glucose-6Phosphate Dehydrogenase Deficiency. Hematol Oncol Clin North Am. 2016;30(2):373-393.

12. Meloni T, Forteleoni G, Dore A, Cutillo S. Favism and hemolytic anemia in glucose-6- phosphate dehydrogenase-deficient subjects in North Sardinia. Acta Haematol. 1983;70(2):8390.

13. Weng YH, Chou YH, Lien RI. Hyperbilirubinemia in healthy neonates with glucose-6-phosphate dehydrogenase deficiency. Early Hum Dev. 2003;71(2):129136.

14. Ghali HH, Mamoori DAA. Hemolysis in children with Glucose-6-Phosphate Dehydrogenase deficiency after ingestion of fava beans; facts predicting severity. Journal of Contemporary Medical Sciences. 2020;6(6):262-266.

15. Kavehmansh Z, Arab A, Abolghasemi H, Torabi S. Fava Bean Ingestion: the Most Important Risk Factor of Hemolysis in G6PD Deficiency in Iran. Iranian Journal of Blood and Cancer. 2016;8(2):38-42.

16. Beutler E. A series of new screening procedures for pyruvate kinase deficiency, glucose-6phosphate dehydrogenase deficiency, and glutathione reductase deficiency. Blood. 1966;28(4):553-562.

17. Jalloh A, Tantular IS, Pusarawati S, Kawilarang AP, Kerong H, Lin K, et al. Rapid epidemiologic assessment of glucose-6-phosphate dehydrogenase deficiency in malaria-endemic areas in Southeast Asia using a novel diagnostic kit. Trop Med Int Health. 2004;9(5):615-23.

18. Piva E, Brugnara C, Spolaore F, Plebani M. Clinical utility of reticulocyte parameters. Clin Lab Med. 2015;35(1):133-163.

19. Riley RS, Ben-Ezra JM, Tidwell A. Reticulocyte enumeration: past \& present. Laboratory Medicine 2001;32(10):599-608.

20. Bain BJ. Diagnosis from the blood smear. N Engl J Med. 2005;353(5):498-507.

21. Risinger M, Kalfa TA. Red cell membrane disorders: structure meets function. Blood. 2020;136(11):1250-1261.

22. Bolton-Maggs PH, Stevens RF, Dodd NJ, Lamont G, Tittensor P, King MJ, et al. Guidelines for the diagnosis and management of hereditary spherocytosis. Br J Haematol. 2004;126(4):455-74.

23. Kaplan M, Beutler E, Vreman HJ, Hammerman C, Levy-Lahad E, Renbaum P, et al. Neonatal hyperbilirubinemia in glucose-6-phosphate dehydrogenase-deficient heterozygotes. Pediatrics. 1999;104(1 Pt 1):68-74.

24. Meloni L, Manca MR, Loddo I, Cioglia G, Cocco P, Schwartz A, Muntoni S, Muntoni S. Glucose6-phosphate dehydrogenase deficiency protects against coronary heart disease. J Inherit Metab Dis. 2008;31(3):412-7.

25. Muntoni S, Muntoni S. Gene-nutrient interactions in G6PD-deficient subjects-implications for cardiovascular disease susceptibility. J Nutrigenet Nutrigenomics. 2008;1(1-2):49-54.

26. Kwok MK, Leung GM, Schooling CM. Glucose6-Phosphate Dehydrogenase Deficiency and Physical and Mental Health until Adolescence. PLoS One. 2016;11(11):e0166192.

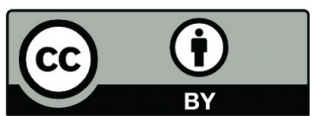

This work is licensed under a Creative Commons Attribution 